tration. An enthusiastic inquiry by $\mathrm{Mr}$ Ogilvy into the activities of the Research Office was met with an apologetic "sorry, that's confidential".

Princess Alexandra, accompanied by Sir Desmond Pond and $\mathrm{Dr} \mathrm{T}$. H. Bewley, and Mr Ogilvy, accompanied by $\mathrm{Dr}$ P. H. Connell and Professor Timbury, closely followed by Lady Mary Fitzalan-Howard, Lady-in-Waiting and Miss Natalie Cobbing, College Secretary, then proceeded to the President's room, where more guests and members of staff were assembled. From here they progressed to the Council Room and adjoining Library, finally arriving in the Warren Suite.

It was particularly gratifying to see among those gathered some of our older Fellows who played such important parts in the transformation of the Royal Medico-Psychological
Association to the Royal College of Psychiatrists. As well as members of the old "Petition Committee", Dr John Howells, Dr J.T. Hutchinson and Dr William Sargant, we were delighted to see past Presidents, Dr L. C. Cook (1958), Dr Martin Cuthbert (1969-71) and Sir Martin Roth (1971-75). Dr Wilfrid Warren, our past Treasurer, was among the first to greet the Royal guest in the newly named Warren Suite, our interchangeable basement lecture theatres, committee rooms and dining area.

Before their departure at $7.30 \mathrm{pm}$, Princess Alexandra and Mr Ogilvy signed the Visitors' Book. Members were then able to wander round the College, meeting old friends and admiring the new decorations in the entrance hall, main staircase, Council Room as well as the Warren Suite.

\title{
The Role of MIND in Relation to Psychiatry*
}

\author{
TONY SMYTHE, National Director, MIND
}

MIND could not function without the help of individual psychiatrists and a basic sympathy and understanding on our part for what psychiatry is trying to achieve.

In summary MIND's aims are the improvement of knowledge about mental health and mental disorder; the encouragement and demonstration of good practice in prevention and treatment; raising the standards of existing services and encouraging new and improved forms of care and treatment; unholding the rights and meeting the needs of patients; mobilizing volunteers; research and the provision of information; providing advisory, counselling, advocacy and, to a limited extent, residential services; maintaining education and training programmes and raising funds both to keep going and to start more mental health projects.

We have a good track record in all these areas but, recognizing the near impossibility of covering the waterfront, we have from time to time picked particular themes to focus our energies and to measure our achievements. These have included the Home and Hospital campaign, which raised the level of accommodation provision for mental patients from 700 in 1976 to 1435 at the end of last year; a campaign for more and better rehabilitation services and employment opportunities; and the 'Alert' campaign on behalf of elderly mental patients. We also have some preliminary ideas for programmes concerned with prevention and day care.

This paper is based on a talk given at the Winter Quarterly Meeting of the College on 10 February 1981. The full text, plus other details of MIND's work are available from MIND, 22 Harley Street, London WIN 2ED.

\section{The mental hospital}

Our dissatisfaction with the mental hospital system is well known and by no means unique. The achievement of modern psychiatry is probably common-ground between us and has certainly been a contributory factor in the steady decline of the mental-illness hospital population. We cannot and do not believe that the large isolated mental hospitals can provide the best kind of therapeutic environment, and we think it regrettable that so little progress has been made towards achieving Enoch Powell's vision of 1961 . We recognize the futility of proposing immediate closures of all large mental hospitals now, but we firmly believe that there has to be a reasonably coherent process of strategic and operational planning. We were alarmed, prematurely, it now seems, by the NHS Royal Commission's expressions of undying faith in the vast majority of existing mental hospitals. At our Annual Conference last year on the 'Future of the Mental Hospitals' we tried to tease out a vision of the next decade. Again, regrettably, few psychiatrists were present. Dearly as many people love their old mental hospitals they are falling apart in every sense. It remains obvious that the function of these hospitals has drastically changed over the last decade, and that in many of them the patient population has declined to the point at which they are hardly viable. The closure or merger of hospitals and the provision of district based alternatives demands realistic consideration.

The mental hospitals continue to provide the focus of political attention and will dictate, for better or for worse, the strategy and measure of service provision. It would be obviously impossible to find alternatives and to plan and 
operate the wider range of community services we need without the advice, collaboration and enthusiasm of mental hospital staff. These are not always forthcoming. Some people feel they could do a better job within the hospital walls or they distrust the competence of those with whom they would have to collaborate. Some of this is very understandable. Mental hospital based professionals and their patients have put up with managerial control from outside, restrictions on initiative, a constant paring away of financial and professional resources, little influence over budgets and planning, innumerable committees with uncertain terms of reference, professional rivalry, co-existent hierarchies that do not even share the same language, territorial disputes, rivalry between unions, the idiosyncrasies of the more institutionalized members of staff, a general lack of direction, and political apathy. They are entitled to feel frustrated or defensive.

But, as we tried to show at the Annual Conference, it is better to be creative than defensive. For example, for as long as the Nodder Committee Report languishes in the recesses of Whitehall we should be provoking a dust-up. The Nodder recommendations may not be perfect but they represent for me the best chance to restore coherence and purpose into a mental hospital service which, however much in need of change, the community still desperately needs. Surely, all mental health interests can unite in campaigning for planned change backed by resources.

\section{Patients' rights}

If that is not controversial, let me turn to another area which has been known to excite adverse psychiatric attention. My predecessor, David Ennals, as Campaign Director, said in 1973, at a symposium entitled 'Psychiatry and the Freedom of the Individual', that 'People do not forfeit their rights as members of the community because they have to go into hospital ... occasionally mental disorder requires restrictions in the interests of the patient and/or the safety of others. However, if people's basic rights are to be over-ridden there must be a clear, relevant and adequate reason for so doing. This is not always the case'. If this is heresy, it came before the appointment of either myself, our Legal Director or the establishment of the MIND legal and welfare rights department all of which have caused some psychiatrists to suggest that MIND has been beset by a civil libertarian plague. MIND was already committed to reasserting its historic role in defending the rights of mental patients and decided to look for a Director with some human rights experience and commitment.

The extraordinary remarks made by the Secretary of State at your last Annual Conference concerning civil liberties tempt me to give you exposition of what civil liberty is about, but I shall merely remind you that mental health has its civil liberty component just as virtually all aspects of society have their civil liberties and mental health components. Civil liberty is about the principles and procedures necessary to redress any imbalance of power between the individual and the state and between the weak and the powerful. None of the great institutions should be allowed to conduct their affairs without independent scrutiny and accountability.

Had the Royal College been quicker to uncover and correct the abuses of power which without any doubt still occur in our institutions, it would not have been so necessary for MIND to be so critical. The system simply does not handle complaints convincingly. It does not provide accessible -and credible procedures for reviewing standards of behaviour and the quality of institutional life and for providing redress when power is abused. You can blame lack of resources, but that gives little comfort to the victims. Rather than acknowledging the gap, MIND has been accused of being legalistic. But it is hardly legalistic to maintain that the affairs of a relatively civilized society are subject to the rules of law. Mental patients suffer certain disadvantages in terms of their legal status. Their relative powerlessness, particularly when they live in institutions, has to be compensated for in some way. We have tried to identify the contentious areas which may or may not require legal intervention but certainly demand a patient's voice. We have sometimes used the limited legal channels already at our disposal such as the courts, tribunals and the European Commission on Human Rights when these seemed to be appropriate remedies for patients or families or staff who asked us to represent their interests.

Indeed, criticisms made against us are not so much to do with using these limited remedies as with winning our cases and attracting publicity.

The fact remains that we are often confronted with problems for which there is no legal remedy. Yet, far from recommending purely legislative solutions or a return to the clammy embrace of the legal profession and the courts, we have preferred to recommend administrative remedies plus more professional self-discipline. Far from giving more work and money to the lawyers, we have trained and organized lay advocacy schemes for which there is little or no financial reward. Certainly, in some of our attempts to suggest ways in which patients, particularly those in long-stay institutions, could acquire help, advice and representation, irrespective of their capacity to articulate and demand their own rights, we have suggested structures and procedures which are open to refinement and negotiation, and we are willing to continue down this road provided we get a more constructive response from those professional people who can distinguish between principles and imagined self-interest.

During the deliberations of the Butler Committee on the Abnormal Offender we realized that the outcome was bound to include some recommendations for legislative change. The 1959 Act needed general overhaul. No complex piece of social legislation could hope to survive for 16 years with almost no amendment or refinement. We decided to open up debate by providing a conceptual framework for radical revision. The first volume of $A$ Human Condition provoked 
the disapproval of psychiatrists, rather than other mental health professionals, and, although some of its solutions were somewhat clumsy, it identified most of the problems and principles. The second volume on abnormal ofienders merely extended the Butler-type thinking. A Human Condition was the first cogent review of the issues and sparked off, as it was intended to do, a wideranging debate. So did the Butler Report. But, like Lord Butler, MIND feels frustrated and affronted that action for reform has been so slow.

It now seems that the Government is prepared to introduce new legislation as soon as parliamentary time is available. It is apparently the view of ministers that, while reform is necessary, there remain some outstanding issues on which advice from interested parties would be welcomeparticularly if we could agree rather more. I am thinking mainly of consent, particularly for compulsorily detained patients, and the kind of trigger-mechanism which would be useful in preserving patients' integrity when, compulsorily detained or not, they are faced with treatments which could be regarded as irreversible, hazardous or unsupported. Recently MIND has instigated further discussions with the DHSS and with the Royal College to discover the extent to which we disagree on fundamentals and the extent to which a consensus view is possible.

\section{MIND's Advisory Service}

Complaints mainly come from mental health workers and we have been severely criticized for pursuing some of these on the grounds of not being thorough or of interference with professional judgement. All I can say is that the internal procedures must be defective if so many people choose to seek the help of a voluntary agency. We have no alternative but to respond to demands from professionals and consumers alike. Many have to be rejected because our investigative resources and access to information are limited. Our legal activity has been objected to, but since we set up our legal department it has become abundantly clear that mental patients seem to encounter legal difficulties more than most, while mental health professionals are not too sure of their legal duties. Problems presented as legal or as complaints frequently turn out to be quite different, but this does not avoid a considerable expenditure of time or the need to provide a shoulder to lean on. All the same, we get more legal cases than we can manage. Tribunal representation and child advocacy services, for example, have attracted a substantial demand which could not possibly be met simply by employing staff and therefore have to depend to some extent on volunteer lawyers and social workers.

The fact is that in a small and carefully controlled way MIND is in the front line in combating the same severe problems which are the bread and butter of professionals. Often we find ourselves dealing with people who are regarded by the statutory agencies as too hot, too boring and too inconvenient to handle. Given that MIND and other voluntary organizations are not always in a position to pick up the tab it is small wonder that so many people are dumped in long-stay institutions of declining quality, special hospitals or prison, or into the oblivion of park benches, railway stations, dosshouses, night-shelters and soup kitchens. I am reminded too that whereas the statutory sector copes with many acute problems and the historical accumulation of the chronically sick and disabled, and whereas the voluntary sector claims to deal with a relatively small proportion of the same sort of people, the fact remains that for every severe case dealt with by us there are many more being cared for at home by their families or not being cared for and left to fend for themselves as best they can. At MIND we see a great deal of community need and too few psychiatric resources. Is it reasonable for psychiatrists to remain locked within a hospital-based structure when there is so much to be done in primary care and preventative work? How can we square the evident need for better care in the hospitals with the relatively new demands and opportunities in, for example, health centres where the psychiatric contribution has been well demonstrated? And even if more such developments are not feasible immediately, what can be done to assist GPs and primary care teams who are-often the gate-keepers to specialist psychiatric care? Maybe these are not the right questions, but they are the sort which occur to the informed observer of the psychiatric scene.

\section{MIND and the Royal College}

A few psychiatrists waste a lot of time in attacking each other and MIND. When MIND discovered the use of unmodified ECT in a certain hospital, our Medical Adviser raised our concerns with your President. We ourselves could not believe the allegation when it was first made and when we first voiced it in professional circles we were greeted with even greater incredulity. The focus of the argument rapidly changed when the truth became known. Given that the Royal College's own guidelines did not even contemplate the use of unmodified ECT, it suddently became a practice which was rare but appropriate in certain circumstances. The sacred cow of clinical judgement was not to be sacrificed, and the Secretary of State said that what was good enough for the Royal College was good enough for the DHSS. MIND apparently had been unfair and irresponsible.

It was all a salutary lesson in the need not to rock the professional boat. I have to confess that I am a slow learner. Now I quite realize that professional solidarity can be noble and that professionals prefer to dispute amongst themselves rather than engage in unseemly debate with the outside world. However, such solidarity may not only provide a cover for incompetence, idleness, eccentricity or error, but can exaggerate the suspicions of the lay community. Sooner or later the psychiatric profession will have to face up to what most other professions have begun to realize. To gain public confidence and credibility you have to explain yourselves and you must not change the rules half-way through 
the game. The very concept of professionalism is becoming debased in the public mind in that so many professionals have gone beyond their remit, which is largely to do with the maintenance of levels of skill, training and ethical standards, to become exclusively preoccupied with self-defence and preservation of arcane knowledge.

We feel that we are often in a position to be of use to the Royal College and its members. MIND is spending a fair amount of money on running the All-Party Parliamentary Mental Health Group to which the Royal College has good access. We think that some of our literature could be helpful to psychiatrists. Our next new venture is to produce a Mental Health Year Book which will try to overcome some of the problems caused by the official time-lag in making data available and the difficulties we all experience in collating useful information which has to be gleaned from different administrative sources. We hope to run a major conference on treatment later this year.

I feel sure that, just as the Royal College has achieved great advances in improving standards of psychiatric training and in encouraging new and important specialties within psychiatry, it could generate rather more enthusiasm for psychiatry among medical students and young people who are considering entering the medical profession. None of us who are aware of the progress made over the last ten to twenty years in modern psychiatry can be complacent when only 40 per cent of junior psychiatrists are trained within the UK and when the profession cannot produce enough consultants to fill all the important posts available.

We look to the Royal College to provide leadership and a focus for mental health and psychiatric concern. Yet we probably need something more than the Royal College and something more than MIND. During a recent visit to the United States I was tremendously impressed by the National Institute for Mental Health, which seems to have the money and the executive power to provide comprehensive information services and to instigate research and service development. If we suggested something similar here it could easily be dismissed as an alien monstrosity or a quango, but such arguments do not obviate the need.

I hope that you will share with me the view that mental health services, including psychiatry, are in crisis which is largely, but not wholly, the product of administrative and political neglect. Mental health represents by far the largest and most serious health and social problem of our time, given that the legislation, the organization of services, the state of the science and the morale of the professions leave a lot to be desired. What is happening to our society, in economic and social terms, is crudely destructive of good mental health, which can only increase demand for psychiatric services. Should we not all in our separate compartments, professions and organizations be generating a more radical and more urgent response? Should we not collectively be demanding of Government that it either provides the resources for us to do what we know needs to be done or that it recognizes the enormity of the issue and sets up a Royal Commission to educate itself and the public and to provide the impetus and the justification for fundamental reorganization and change?

\title{
Confidentiality: Minors Assessed by Multidisciplinary Teams
}

\author{
Jean Harris, Consultant Psychiatrist, Child and Family Psychiatric Service, Dunstable
}

This article is based on work undertaken at the request of my fellow members of a DHSS Working Party chaired by Professor Norman Tutt, Department of Applied Social Studies at the University of Lancaster. The terms of reference were: 'to consider observation and assessment services for children and young persons referred to local authority Social Services Departments; to clarify the role of observation and assessment centres; to consider the promotion of non-residential observation and assessment; to consider what improvements in present assessment practice might be helpful or necessary and to make recommendations'. The report is currently in its final draft and has been sent to the DHSS for approval; and, since my contribution has necessarily been compressed into a few paragraphs, my colleagues suggested that I should seek an additional route to publication.

In attempting to elaborate this theme, it is not difficult to find references which are tangentially relevant, or which enable the formulation of appropriate questions, but it is less easy to find previously published specific guidelines. This topic may be approached in several ways:

(I) From the standpoint of a multidisciplinary team working (a) in a residential setting supplied with offices, secretarial staff, and telephones, such as a hospital, special school or assessment centre managed by a Department of Social Services; or (b) within a community-based network of services for children.

(II) From the standpoint of (a) a child/client under 18 years of age; or (b) his parents or legal guardians.

The Royal College of Psychiatrists (1977a) has published guidelines which, though meant for psychiatrists working with adult patients in National Health Service settings, 